Journal of the Scholarship of Teaching and Learning, Vol. 20, No. 1, April 2020, pp.85-104.

doi: $10.14434 /$ josotl.v20i1.25423

\title{
The Impact of Undergraduate Research and Student Characteristics on Student Success Metrics at an Urban, Minority Serving, Commuter, Public Institution
}

\author{
Sheila I Baron \\ University of Iowa, Statistics Outreach Center \\ sheila-barron@uiowa.edu \\ Pamela Brown \\ New York City College of Technology, City University of New York \\ pbrown@citytech.cuny.edu \\ Tammie Cumming \\ Brooklyn College, City University of New York \\ Michelle Mengeling \\ University of Iowa, Statistics Outreach Center \\ michelle.mengeling@gmail.com
}

\begin{abstract}
Challenges to establishing and maintaining undergraduate research programs include how to demonstrate impact as evidence for future funding, establish eligibility criteria when resources are limited, and assess new components. To address these challenges, undergraduate researcher GPA, credit accumulation and time to graduation were evaluated longitudinally, at an urban, public, minority and Hispanic serving, commuter college. Students who participated in undergraduate research and matched peers were also compared. Evaluation revealed that all groups benefited from participation in undergraduate research, whether they had full- or part-time status, were STEM or non-STEM majors, or participated in single or multiple semesters of research. Addition of mandatory workshops after the fourth year of the seven years of students evaluated, correlated with longer participation in voluntary undergraduate research. Longer participation correlated with higher GPAs. Entering freshmen and transfer students, who began research with no College GPA, were more likely to have low GPAs during the semester of participation, suggesting that a successful semester at the college before eligibility may be an evidence-based criteria to implement.
\end{abstract}

Keywords: undergraduate research, underrepresented groups, part-time students, STEM, nonSTEM, eligibility criteria

\section{Introduction}

A key factor to whether college students persist and thrive is the degree to which they participate in educationally effective activities that contribute to their learning, personal development and success (Kuh, 2001; Kuh, 2003; Lopatto, 2006). Undergraduate research is a recognized high impact pedagogical practice that enhances student development and results in increased retention and degree completion; it has been identified as particularly important to the academic success of underrepresented groups. Undergraduate research experiences have been demonstrated to support STEM-related career aspirations and increase STEM graduation rates (Gregerman et al, 1998; Davis, 2009; Espinosa, 2011; Hu et al, 2008; Johnson, 2011; Schultz et al, 2011; Ishiyana and Hopkins, 2005; Seymour et al, 2004; Laursen et al, 2010). 